\title{
E-LEARNING COMO FERRAMENTA DIGITAL NO ENSINO HÍBRIDO: UMA METODOLOGIA COLABORATIVA NA FORMAÇÃO TÉCNICA
}

\section{E-LEARNING AS A DIGITAL TOOL IN HYBRID EDUCATION: A COLLABORATIVE METHODOLOGY IN TECHNICAL TRAINING}

\section{EL APRENDIZAJE ELECTRÓNICO COMO HERRAMIENTA DIGITAL EN LA EDUCACIÓN HÍBRIDA: UNA METODOLOGÍA COLABORATIVA EN LA FORMACIÓN TÉCNICA}

Ricael Spirandeli Rocha ${ }^{1}$ Gustavo Prado Oliveira ${ }^{2}$ Gyzely Suely Lima ${ }^{3}$

Submetido em: 23/03/2020 - Aceito em: 27/05/2020 - Publicado em: 18/08/2020.

\begin{abstract}
${ }^{1}$ Secretaria Estadual de Educação de Minas Gerais (SEE/mg) - Professor; Instituto Federal de Educação, Ciência e Tecnologia de Minas Gerais - Campus Avançado Arcos (IFMG - ARCOS) - Tutor a distância Instituto Federal de Educação, Ciência e Tecnologia do Triangulo Mineiro - Campus Uberlândia Centro(IFTM-Udi Centro) - Aluno Pós-graduação.Discente do curso de Pós-Graduação Lato sensu em Tecnologia, Linguagens e Mídias em Educação pelo Instituto Federal de Educação, Ciência e Tecnologia do Triângulo Mineiro (IFTM) campus Uberlândia Centro; Especialista em Produção de Materiais Didáticos Utilizando o Linux Educacional pela Universidade Federal de Lavras - UFLA (2018);Graduado em Computação pelo Instituto Federal de Educação, Ciência e Tecnologia do Triângulo Mineiro - IFTM- (2017);Tutor em Educação a Distância no Instituto Federal de Educação, Ciência e Tecnologia de Minas Gerais (IFMG) campus avançado Arcos. Professor Designado de Computação no Centro de Orientação e Pesquisa em Educação Espcial - CEOPEE pela Secretaria Estadual de Minas Gerais (SEE/MG);
\end{abstract}

${ }^{2}$ Instituto Federal do Triângulo Mineiro, Instituto Federal do Triângulo Mineiro.Possui graduação em Ciência da Computação pela Universidade Federal de Goiás (2003) e mestrado em Engenharia Mecânica pela Universidade Federal de Uberlândia (2007). Atualmente é prof. do ensino basico tecnico e tecnologico do Instituto Federal de Educação Ciência e Tecnologia do Triângulo Mineiro. Tem experiência na área de Ciência da Computação, com ênfase em Programaçao e Engenharia de software, atuando principalmente nos seguintes temas: programação, tecnologia da inforamção, programação comercial, engenharia de Software e sistemas para internet.

3 Instituto Federal do Triângulo Mineiro, Instituto Federal do Triângulo Mineiro. Doutora em Estudos Linguísticos (2016) pela Universidade Federal de Uberlândia. Possui o título de Mestre em Letras na área de Teoria Literária (2010) pela Universidade Federal de Uberlândia. Atualmente atua como professora efetiva no Instituto Federal do Triângulo Mineiro- IFTM- campus Uberlândia Centro. Os seguintes temas são estudados e 


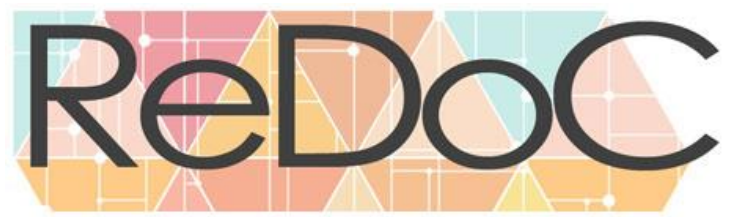

Revista Docência e Cibercultura

\section{RESUMO}

Com base nas tecnologias que estão cada vez mais em evidência, o $e$-learning (aprendizado eletrônico) contribui no incentivo e disposição do acesso à informação no processo de ensino e aprendizagem. O objetivo deste trabalho é evidenciar a utilização do e-learning como ferramenta digital no ensino híbrido em um contexto pedagógico e colaborativo na formação técnica. Refere-se a um relato de experiência de caráter descritivo e exploratório com uma abordagem quanti-qualitativa. Dessa forma, resultados apontaram que a utilização do $e$ learning contribui no processo de construção do conhecimento em conjunto de aprendizagem híbrida e colaborativa, proporcionando significativo desempenho, liberdade e autonomia dos estudantes.

Palavras-chave: E-learning. Metodologia híbrida. Aprendizagem colaborativa.

\section{ABSTRACT}

Based on technologies that are increasingly in evidence, e-learning (e-learning) contributes to encouraging and providing access to information in the teaching and learning process. The aim of this work is to highlight the use of e-learning as a digital tool in hybrid teaching in a pedagogical and collaborative context in technical training. It refers to an experience report of a descriptive and exploratory character with a quantitative and qualitative approach. Thus, results showed that the use of e-learning contributes to the process of building knowledge in conjunction with hybrid and collaborative learning, providing significant performance, freedom and autonomy for students.

Keywords: E-learning. Hybrid methodology. Collaborative learning.

\section{RESUMEN}

Basado en tecnologías cada vez más evidentes, el e-learning contribuye a alentar y proporcionar acceso a la información en el proceso de enseñanza y aprendizaje. El objetivo de este trabajo es resaltar el uso del e-learning como una herramienta digital híbrida en un contexto pedagógico y colaborativo en la formación técnica. Se refiere a un informe de experiencia de carácter descriptivo y exploratorio con un enfoque cuantitativo y cualitativo. Por lo tanto, los resultados mostraron que el uso del aprendizaje electrónico contribuye al proceso de construcción de conocimiento junto con el aprendizaje híbrido y colaborativo, proporcionando un rendimiento significativo, libertad y autonomía para los estudiantes.

Palabras clave: E-learning. Metodología híbrida. Aprendizaje colaborativo.

\section{INTRODUÇÃO}

Diante de vários aspectos pedagógicos e educacionais, as ferramentas digitais propõem um amplo processo que se caracteriza na inserção do aluno como um nativo ou

objetos de pesquisa: colaboração, pesquisa narrativa, ensino de língua inglesa, tecnologias digitais, literatura comparada, literatura e cinema, linguística aplicada ao ensino de língua inglesa e língua portuguesa, língua inglesa, letramentos, papel do professor e literatura. 


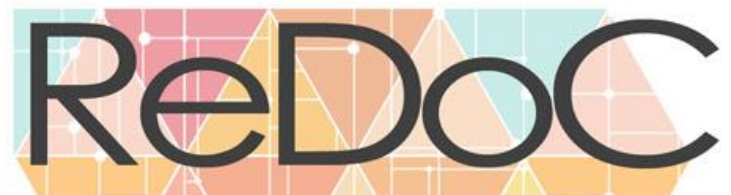

\section{Revista Docência e Cibercultura}

imigrante digital (PRENSKY, 2001), colaborando de forma centrada onde o próprio aluno se auto compromete na ciência do aprender.

Contudo, é possível perceber que práticas pedagógicas tradicionais que remetem em apenas utilizar tecnologias passadas como o quadro negro e giz, vêm sendo pouco estimadas pelos alunos (BACICH; MORAN, 2018).

Nota-se que a escola deixa de ser a única fonte de conhecimento, uma vez que o advento da internet propicia a popularização do acesso a tecnologias no contexto digital. Para Sunaga e Carvalho (2015), a escola de hoje tem papel expansor onde não finda o aprendizado, mas sim, direciona e prepara os estudantes a trilhar de forma consciente e responsável novos caminhos.

Nesse sentido, o letramento digital torna-se relevante no processo de ensino e aprendizagem de professores e estudantes que apresentam a demanda social de assumir o papel de engajamento na sociedade em que estão inseridos (ROJO, 2007).

Ademais, reconfigurações de propostas de ensino vêm ganhando espaço e se fortalecendo, com distintas propostas de ensino e aprendizagem no contexto escolar. Para Belloni (2001), vários campos educacionais como a Educação a Distância (EAD) contribuem corroborando como uma nova forma de ensinar, transformando práticas educacionais com incentivo ao uso de novas tecnologias no contexto pedagógico.

Nessa perspectiva pode-se refletir sobre como os professores e profissionais da educação têm almejado oferecer um ambiente de aprendizagem rico e harmonioso, de modo que os alunos tenham vontade de permanecer, instigando-os, possibilitando-lhes criar novos meios de informação e transformando em conhecimento, interagindo com tecnologias e colaborando com seus pares (BACICH; MORAN, 2018).

Partindo dessa contextualização, este artigo objetiva apresentar um relato de experiência de ensino híbrido, que utiliza o e-learning como plataforma pedagógica digital, no contexto escolar de uma turma do curso técnico em Recursos Humanos, especificamente na disciplina de Português Instrumental, ofertado em uma escola estadual da cidade de Uberaba/MG. A proposta de ensino visou colaborar com processo de ensino e aprendizagem 


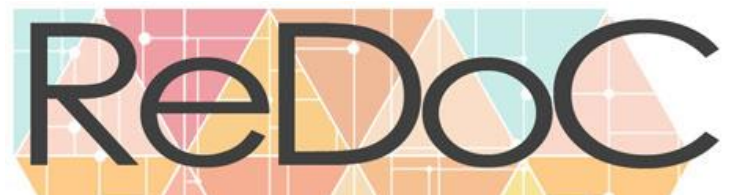

\section{Revista Docência e Cibercultura}

permeado por ferramentas digitais, caracterizando-se com uma metodologia híbrida e colaborativa, a fim de motivar e engajar os alunos no ambiente escolar.

Frente a esse contexto, o Google sala de aula foi adotado como solução computacional, com o propósito de se tornar um ambiente virtual de aprendizagem (AVA), para disciplina parcialmente a distância, caracterizando a junção de práticas presenciais e $\mathrm{EaD}$, como um ensino e aprendizado híbrido.

Destarte, foi realizado um estudo quanti-qualitativo sobre a utilização do e-learning como ferramenta educacional, desejando evidenciar a prática de ensino e aprendizagem sob um contexto híbrido, gerando uma análise relevante a partir do seu uso e por uma metodologia colaborativa a fim de ser aproveitado para novas experiências e reproduzir com outros conteúdos.

\section{O E-LEARNING NA PERSPECTIVA PEDAGÓGICA}

Muito tem sido discutido sobre a estrutura educacional nos últimos anos, onde o uso de tecnologias digitais vem sendo inseridas no contexto escolar, muita das vezes de forma ainda tímida proporcionando novos meios de ensinar.

Mediante essa realidade, Lévy e Authier (2000) apontam uma proposta tecnológica como um fator agregador, possuindo importante papel de transformação a partir do conhecimento, fácil acesso e o intuito colaborativo.

O e-learning é uma viável ferramenta digital pois, é "frequentemente perspectivado como uma extensão da sala no espaço virtual da Internet (ou outros ambientes de rede)" (GOMES, 2005, p. 232).

No entanto, ainda existe uma diversidade de conceitos a respeito do termo, confundindo-o com a Educação a Distância (EaD). Dessa forma Cardoso (2007) determina que $e$-learning é uma expressão em inglês que significa aprendizado eletrônico. Ele se baseia na utilização do computador e conta com um grande número de ferramentas avançadas e poderosas.

Todavia, outras definições podem ser encontradas como "modalidade de ensino e aprendizagem que pode representar o todo ou uma parte do modelo educativo em que se 


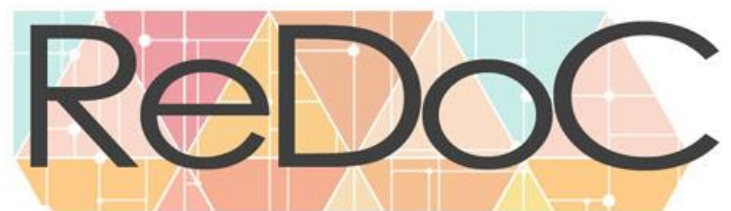

\section{Revista Docência e Cibercultura}

aplica, que explora os meios e dispositivos eletrônicos para facilitar o acesso, a evolução e a melhoria da qualidade da educação e formação" (SANGRÀ et al, 2011, p.35).

Ruhe e Zimbro (2015, p.18) também define e-learning como: "programa instrucional distribuído online ou pela internet. Inclui tutoriais distribuídos no campus universitário, workshops, curso de curta duração e instrução realizada no local de trabalho".

Mesmo com uma definição muito próxima, a Educação a Distância possui sua particularidade, sendo "um termo genérico e de significado bastante amplo, usado para designar a separação física entre professores e alunos" (SCHLOSSER; SIMONSON, 2009, p. $65)$.

Não obstante, o atual Decreto n ${ }^{\circ} 9.057$ de 25 de maio de 2017 considera:

Educação a Distância a modalidade educacional na qual a mediação didáticopedagógica nos processos de ensino e aprendizagem ocorra com a utilização de meios e tecnologias de informação e comunicação, com pessoal qualificado, com políticas de acesso, com acompanhamento e avaliação compatíveis, entre outros, e desenvolva atividades educativas por estudantes e profissionais da educação que estejam em lugares e tempos diversos. (BRASIL, 2017).

Dessa maneira, a EaD caracteriza-se por um histórico evolutivo, desde cursos por correspondências sem nenhuma utilização de tecnologia digital de informação e comunicação, avançando para experiências radiofônicas e programas televisivos com projetos educacionais, até chegar na atual inserção das Tecnologias Digitais de Informação e Comunicação (LOPES, 2011).

A partir de toda dinâmica que o e-learning oferece, é importante ressaltar que esse recurso se divide em dois tipos de ambientes:

\footnotetext{
Assíncronos, tais como podcasting ou discussões online, permitem a autogestão da aprendizagem a qualquer hora e em qualquer lugar. Os ambientes de e-learning síncronos são caracterizados por diferentes tipos de interação por meio de chats, áudio em tempo real, compartilhamento de aplicativos, whiteboards, webcasting, vídeo teleconferência e assim por diante[...]” (RUHE; ZUMBO, 2015, p. 19).
}

Consequentemente, o e-learning utiliza-se de ambos recursos de forma colaborativa, afim de integrar ensino e aprendizagem em um mesmo momento. Todavia, essa aplicabilidade é usualmente encontrada na educação a distância, facilitando a integração dos ambientes em e-learning a uma expressiva aprendizagem. 


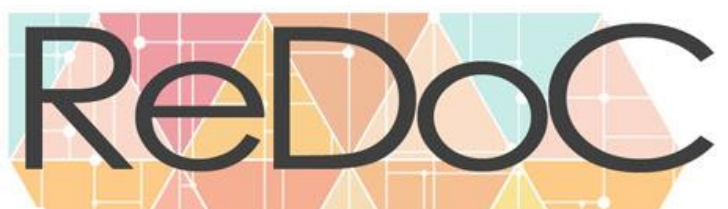

\section{Revista Docência e Cibercultura}

Destacando aspectos tecnológicos, "professores em sala de aula utilizam cada vez mais tecnologia para oferecer programa de aprendizado individual para estudo fora da sala de aula, afim de apoiar métodos face a face para grupos" (MOORE, 2007, p. 2).

Idealmente, a aprendizagem a distância contribui para o estímulo de independência e seriedade do aluno, além de potencializar o aprendizado individual e colaborativo. Moore (2007, p. 244), ainda afirma, "quanto maior a interação a distância, mais o aluno tende a exercer tal responsabilidade", construindo dessa forma, com aspectos de autonomia educacional.

\subsection{A utilização do e-learning como ferramenta digital híbrida}

$\mathrm{Na}$ era digital, as atuais metodologias estão utilizando a tecnologia como ferramentas digitais. O e-learning têm se mostrado um recurso digital que vem ganhando espaço nos processos educacionais.

Segundo Clark e Mayer (2003), o e-learning é uma metodologia distribuída em forma de treinamento que contribui para melhorar a performance individual, sendo assim, uma valorosa ferramenta aplicável no âmbito educacional.

A vista disso, Castells (2009), já antecipava esse cenário a partir da sociedade interligada em rede, evidenciando a sociedade interativa a partir da comunicação intervinda da internet, ressaltando como fenômeno social e contribuindo para academia.

Em meio a era tecnológica, a Educação a Distância (EaD) surge como uma modalidade de ensino que consegue romper paradigmas de pensamento. Para Pereira e Moraes (2009) a EaD concretiza a facilidade de estudar em relação ao tempo, mediado pela tecnologia e meios digitais.

Nesse sentido, duas propostas educacionais distintas se fundem, nascendo uma nova ideia de ensino e aprendizagem. O ensino híbrido é a metodologia que nasce a luz de trazer configurações do ensino presencial reunido com tecnologias do ensino a distância, caracterizando-se como uma junção metodológica que aciona ativamente a dinâmica no professor com práxis educacionais, e na conjuntura dos alunos no processo de ensino e aprendizagem (BACICH; TANZI NETO; TREVISANI, 2015). 
O ensino híbrido também é caracterizado pelo fato de reunir tecnologias digitais de informação e comunicação (TDIC) com abordagens pedagógicas no ensino presencial, Valente (2015) destaca o ensino híbrido como uma solução benéfica onde o aluno possui uma conexão com o material instrucional antes de inserir-se na sala de aula, dessa forma:

\begin{abstract}
O estudante tem contato com as informações antes de entrar em sala de aula. A concentração nas formas mais elevadas do trabalho cognitivo, ou seja, aplicação, análise, síntese, significação e avaliação desse conhecimento que aluno construiu ocorre em sala de aula, onde ele tem o apoio de seus pares e do professor (VALENTE, 2015, p. 15).
\end{abstract}

A partir desse contexto, o ensino híbrido configura-se como uma proposta inovadora a fim de contribuir com o processo de ensino e aprendizagem dos alunos, concentrando tecnologias digitais como e-learning. Além disso, representa uma possibilidade e personalização do ensino corroborando no contexto educacional (BACICH; TANZI NETO; TREVISANI, 2015).

Nessa continuidade, a utilização do e-learning como ferramenta digital, agregado com uma finalidade dupla de ensino a distância com o presencial, remete-se a um modelo totalmente híbrido.

O processo educacional sempre foi constituído de compostas combinações de vários fatores tais como: tempo; culturas; espaços; pensamentos. Para uma melhor compreensão do termo, híbrido significa mistura, mesclado, blended, formando assim o termo blended learning ou b-learning (MORAN, 2015).

É importante ressaltar que, o b-learning nasce a partir de uma inovação metodológica, não pretendendo impor nenhum modelo pré-estabelecido para que, unidades escolares sigam estritamente, mas sim, contribuir com apoio interativo e tecnológico que o ensino híbrido propõe, rompendo práticas obsoletas e conservadoras a partir de modelos pedagógicos inovadores no emprego da educação híbrida (MORAN, 2015).

\title{
2.2 O uso do e-learning na aprendizagem colaborativa
}

O professor, desde o princípio assume o papel de ensinar, com isso, formas convencionais e arcaicas de ensino aprendizagem vem sendo reprovados como uma 


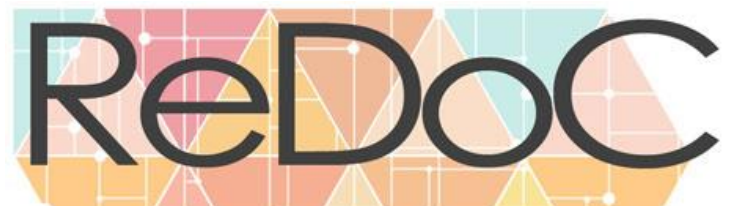

\section{Revista Docência e Cibercultura}

abordagem didática ineficiente, refletindo na promoção do processo de ensino e aprendizagem do estudante.

Para Bransford et al., (2000), centralizar o professor como única forma de conhecimento pode ser útil para transpor aprendizagem em um curto espaço de tempo, contudo, tal método de ensino estimula os estudantes a aprender superficialmente sem estar dinamicamente envolvidos.

Com isso, nasce a sensibilização do professor em criar estratégias imersivas que contribuem com engajamento dos alunos. A aprendizagem colaborativa é uma estratégia muito evidente na atualidade; uma vez que "na aprendizagem colaborativa os estudantes trabalham em pequenos grupos para discutir conceitos e encontrar soluções para os problemas" (MOURA, 2017, p. 13).

Desse modo, o professor começa a assumir um novo papel na formação dos alunos, onde sua figura não é mais vista como antes, traduzindo uma nova forma de ensinar e principalmente de mediar novas tecnologias no cotidiano dos estudantes. Castro (2018), ressalta que:

Para auxiliar na realização de atividades colaborativas, o desenvolvimento da tecnologia digital se apresenta de modo positivo, pois é possível que, devido ao grande número de plataformas virtuais de aprendizagem e ferramentas já existentes, elas possam ser usadas e contribuam para a execução destas atividades. (CASTRO, 2018, p. 16).

Nesse sentindo, o enfoque desse modelo consiste estrategicamente em centralizar o aluno no processo de ensino e aprendizagem, descentralizando o professor como único detentor de conhecimento. O e-learning associa a tecnologia empregada de forma colaborativa, considerando características participativas de aprendizagem como verdadeiro recurso interativo (MARTINS, et al., 2012).

\section{PRESSUPOSTOS METODOLÓGICOS}

A asserção metodológica caracteriza-se como relato de experiência, de caráter descritivo pois, aborda a observação dos fatos, caracterizando-se em registrar, analisar, classificar e interpretar os dados, onde o aplicador não interfere neles, e também exploratória, 


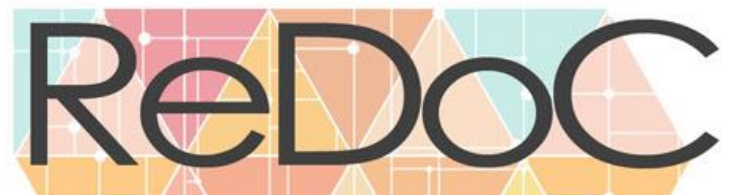

\section{Revista Docência e Cibercultura}

visto que, consiste em proporcionar maiores informações sobre o assunto pesquisado, evidenciando a delimitação do tema e descobrindo uma nova perspectiva sobre o assunto (ANDRADE, 2002).

A premissa do trabalho ocorreu na produção de uma sequência didática aplicado como e-learning, onde essa é um "modo do professor organizar as atividades de ensino em função de núcleos temáticos e procedimentais" (DE ARAUJO, 2013, p. 323).

O e-learning foi utilizado como Ambiente Virtual de Aprendizagem (AVA) pela ferramenta Google sala de aula. Witt (2015), destaca que o Google classroom (nome americano do Google sala de aula) é um ambiente virtual no estilo sala de aula, onde o administrador que geralmente é o professor, ou responsável pela turma, organiza conteúdos, direciona trabalhos, acompanha o desenvolvimento dos alunos a partir de textos, enquetes, vídeos, áudios entre outros, caracterizando um ensino virtual.

A sequência didática foi aplicada na disciplina de Português Instrumental do curso técnico em Recursos Humanos, realizado em uma escola estadual de Uberaba/MG, contando exatamente com uma turma de 31 alunos do período noturno, extremamente heterogênea, com idades entre 16 até 48 anos, onde a grande maioria realizava alguma atividade remunerada ou completava o ensino médio.

O relato de experiência também traz uma abordagem qualitativa, baseada em pequenas amostras que proporcionam percepções e compreensão do contexto do problema (GIL, 2008). Além de dados quantitativos, evidenciando elementos contextualizados em acontecimentos e interpretações de dados em âmbito processual, refletindo continuamente sobre compreensão e comportamentos perante a interação dinâmica do agente de estudo (MAYRING, 2002).

\section{RESULTADOS E DISCUSSÃO}

A aplicação do e-learning usando o Google sala de aula, permitiu identificar boa aceitação da turma, evidenciando o uso por todos os alunos, tanto na aula presencial como virtual. 


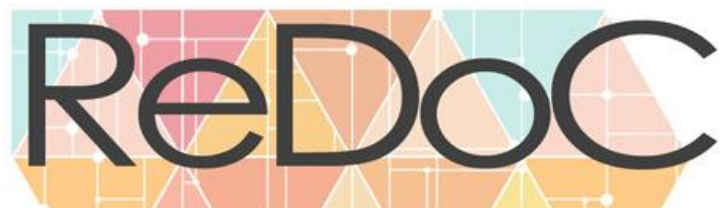

\section{Revista Docência e Cibercultura}

Em cada fase da sequência didática foi elaborado uma atividade como resultado do uso do e-learning juntamente com a metodologia de aprendizagem colaborativa. A sequência didática foi fragmentada em três momentos distintos, iniciando a execução, no início de agosto de 2019 no primeiro bimestre e primeiro módulo do curso, com a atividade denominada fórum de discussão. No segundo bimestre as atividades denominadas missão textual e glossário colaborativo foram executadas. O quadro 1 evidencia esse processo:

\begin{tabular}{|l|l|l|l|}
\hline BIMESTRE & $\begin{array}{c}\text { ATIVIDADE } \\
\text { UTILIZANDO } \\
\text { E-LEARNING }\end{array}$ & METODOLOGIAS & \multicolumn{1}{c|}{ TEMPO ESTIMADO } \\
\hline $\mathbf{1}^{\mathbf{0}}$ & Fórum de discussão & $\begin{array}{l}\text { Híbrida } \\
\text { Colaborativa }\end{array}$ & $\begin{array}{l}\text { - Uma aula dupla presencial de } 50 \text { minutos } \\
\text { - Uma semana de produção } \text { on-line (EaD). }\end{array}$ \\
\hline $\mathbf{2}^{\mathbf{0}}$ & Missão Textual & $\begin{array}{l}\text { Híbrida } \\
\text { Colaborativa }\end{array}$ & $\begin{array}{l}\text { - Uma aula dupla presencial de } 50 \text { minutos } \\
\text { - Três dias de produção } \text { on-line (EaD). }\end{array}$ \\
\hline $\mathbf{3}^{\mathbf{0}}$ & $\begin{array}{l}\text { Glossário } \\
\text { Colaborativo }\end{array}$ & $\begin{array}{l}\text { Híbrida } \\
\text { Colaborativa }\end{array}$ & $\begin{array}{l}\text { - Uma aula dupla presencial de } 50 \text { minutos } \\
\text { - Uma semana de produção } \text { on-line (EaD). }\end{array}$ \\
\hline
\end{tabular}

Fonte: Elaborado pelo autor, com base na pesquisa realizada.

Inicialmente antes de aplicar a primeira atividade, todos os alunos foram inseridos na sala de aula do Google classroom, com cadastro do e-mail. Por se tratar de uma plataforma virtual, verificou-se que todos os participantes interagiram de forma ativa, acessaram a ferramenta e estudaram os materiais postados, pressupõem um efeito significativo que o ambiente gerou na turma, pois, se disciplinaram e concentraram ao explorar a ferramenta.

Após a turma se habituar com a plataforma, estudar os conteúdos postados e explorar suas ferramentas. Foi aplicado a primeira atividade denominado fórum de discussão, o intuito dessa primeira atividade foi aproximar a turma e criar uma dinâmica colaborativa utilizando e-learning através de discussão assíncronas iniciando presencialmente na sala de aula e continuando on-line, a distância, onde o professor provoca a discussão com o objetivo de dialogar e discutir sobre um determinado contexto do português instrumental, de forma clara, objetiva e respeitosa.

Para que o fórum de discussão colaborativo ocorresse, pensou-se em uma problemática textual sobre o conteúdo tipologia textual, além de regras para postagens como: comentar pelo menos duas vezes sobe a opinião do colega; ser gentil e educado nas 


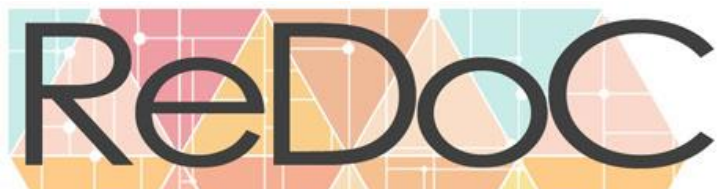

\section{Revista Docência e Cibercultura}

postagens; participar dentro do prazo; escrever de forma correta sem utilizar abreviações e gírias; e principalmente não copiar da internet.

A figura 1 destaca a primeira atividade criada utilizando o Google sala de aula.

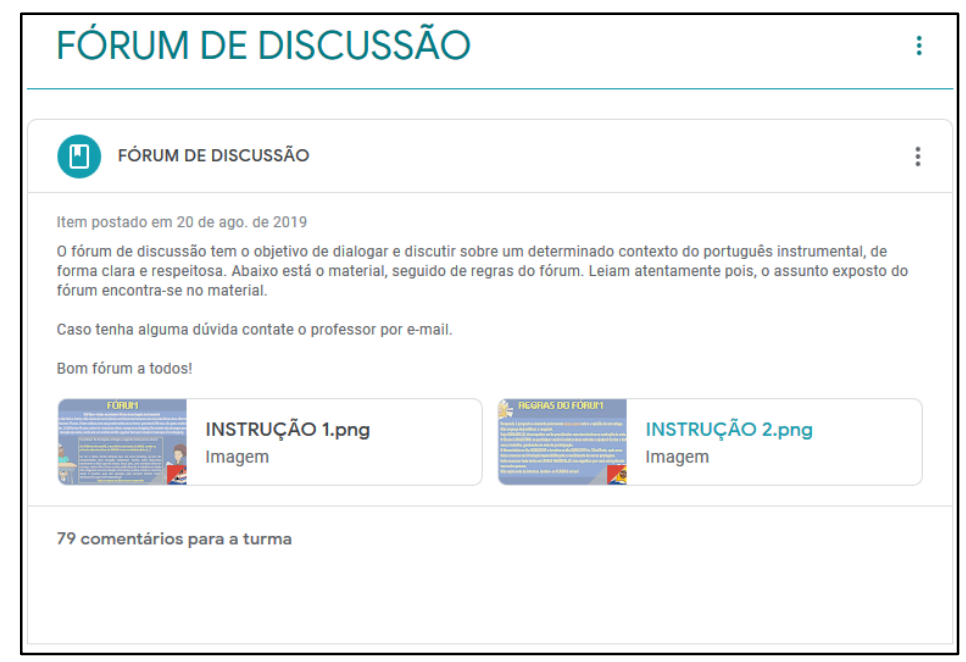

Figura 1 - Atividade fórum de discussão criado com Google classroom. Fonte: Elaborado pelo autor, com base na pesquisa realizada.

Como resultado da primeira atividade, 79 comentários totalizaram a participação efetiva dos alunos, onde cada estudante realizou no mínimo dois comentários. Um ponto importante observado, foi a quantidade de comentários efetuados na aula presencial, onde a maioria dos alunos geraram somente um comentário, aguardando o desdobramento do fórum, visto que, somente a distância que o fórum ficou mais participativo. Todo contexto gerou uma aprendizagem colaborativa, onde cada aluno contribuía com algum conhecimento sobre a disciplina.

No segundo momento da sequência didática, foi aplicado atividade utilizando o formulário Google. Essa ferramenta possibilita a criação de formulários de forma dinâmica e interativa, possibilitando a inserção de imagens e vídeos, recursos dissertativos e de múltipla escolha que lembra bastante uma avaliação tradicional.

Para que os estudantes ficassem mais engajados, criou-se um cenário lúdico, a utilização do aplicativo Bitmoji auxiliou na criação dos avatares, além disso, foram 


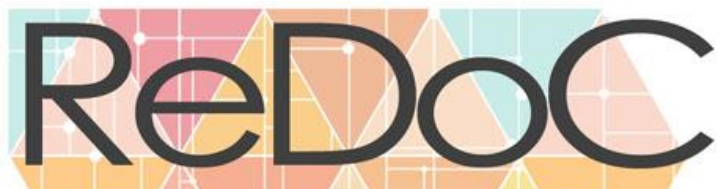

\section{Revista Docência e Cibercultura}

construídas problematizações voltadas para o curso técnico em Recursos Humanos aplicando o conteúdo da disciplina de Português Instrumental.

Nessa proposta, foi realizado atividade em dupla com o colega onde, trocava-se informações a fim de resolver a atividade, no entanto, cada aluno enviou sua própria atividade. Dessa forma, enquanto um estudante resolvia a atividade o outro colaborava, logo em seguida; invertia-se a ordem. A figura 2 destaca a atividade "Missão Textual".

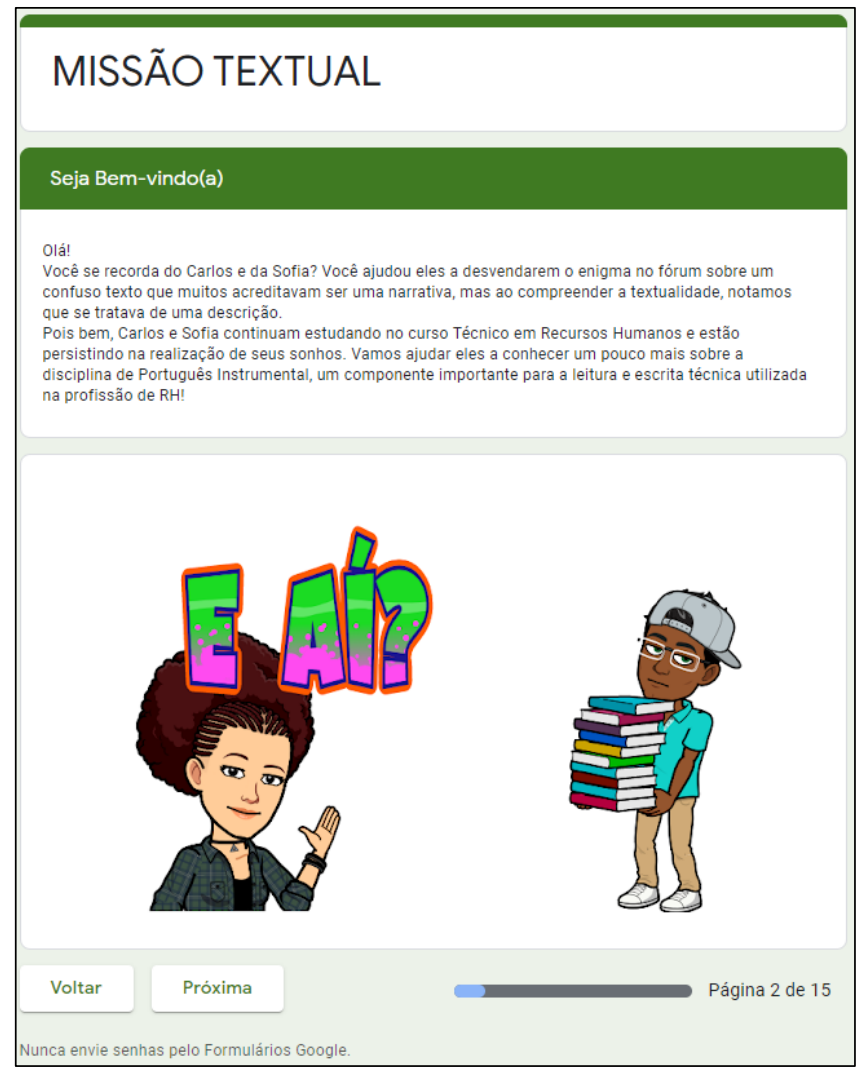

Figura 2 - Missão Textual - criado no Google classroom pelo Google forms.

Fonte: Elaborado pelo autor, com base na pesquisa realizada

Com o objetivo de compreender se o e-learning estava sendo aceito de forma positiva pela turma, ao encerrar a atividade existia uma pergunta de pesquisa de opinião, de forma anônima sem nenhuma identificação, indagando se os alunos estavam gostando da atividade.

A figura 3 mostra o gráfico gerado pelas respostas. 


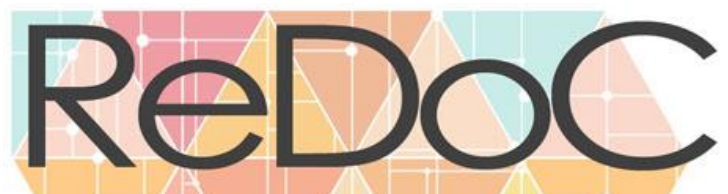

Revista Docência e Cibercultura

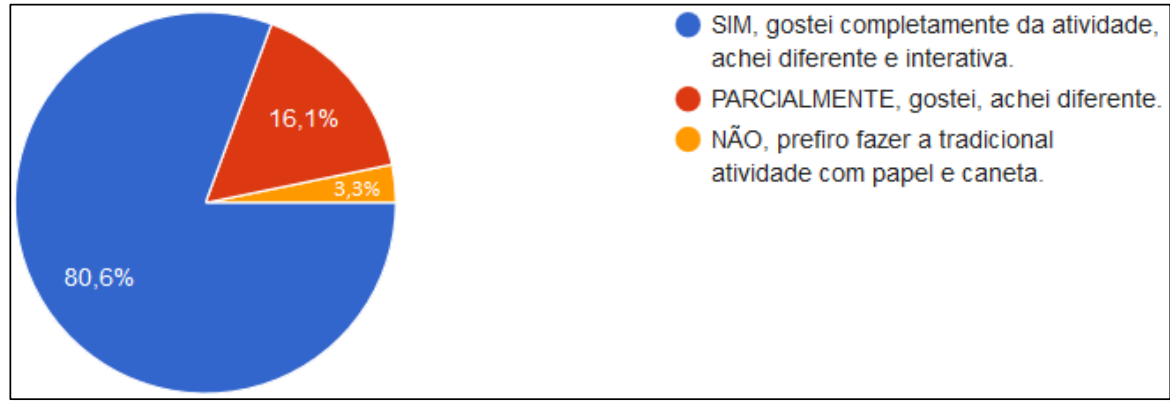

Figura 3 - Utilização do e-learning de forma híbrida, gerado pelo Google forms. Fonte: Elaborado pelo autor, com base na pesquisa realizada.

Os dados evidenciam que $80,6 \%$ dos alunos responderam que gostaram completamente da atividade, achando diferente e interativa, caracterizando uma considerável parcela dos estudantes. Já 16,1\% afirmaram que gostaram parcialmente, achando a atividade utilizando e-learning apenas diferente. E apenas uma pequena fração de alunos com 3,3\% afirmaram que preferem atividades utilizando o tradicional papel e caneta, não aderindo a essa modalidade.

Na última etapa da sequência didática, foi proposto a criação de um glossário colaborativo, ou seja, uma lista de palavras pouco conhecidas em ordem alfabética. Essa atividade fundamentava-se a partir de um documento criado pelo professor utilizando o Google documentos. Essa ferramenta faz parte do Google sala de aula e consegue reunir vários estudantes editando o mesmo arquivo.

A proposta do glossário colaborativo foi inserir palavras pertinentes ao curso técnico em Recursos Humanos, onde um aluno pesquisava um termo e o significado, e outro aluno ao ler o conceito colaborava com um comentário ou a referência de um texto on-line que caracterizava o termo.

A primeira coluna do glossário continha espaço para que o aluno inserisse seu nome, dessa forma, todos saberiam quem estava contribuindo na pesquisa da palavra, no entanto, o comentário realizado era anônimo para que houvesse interação com toda turma e não apenas da dupla. 


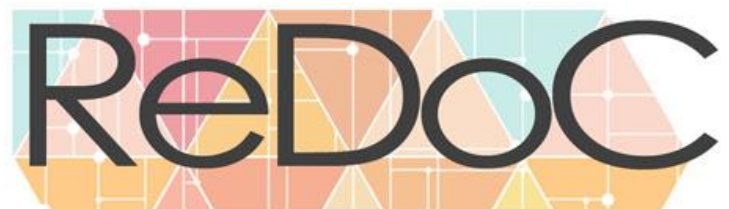

\section{Revista Docência e Cibercultura}

A figura 4 mostra o glossário colaborativo criado no Google sala de aula, utilizando a ferramenta documentos Google, os nomes dos alunos foram apagados para preservar sua identidade.

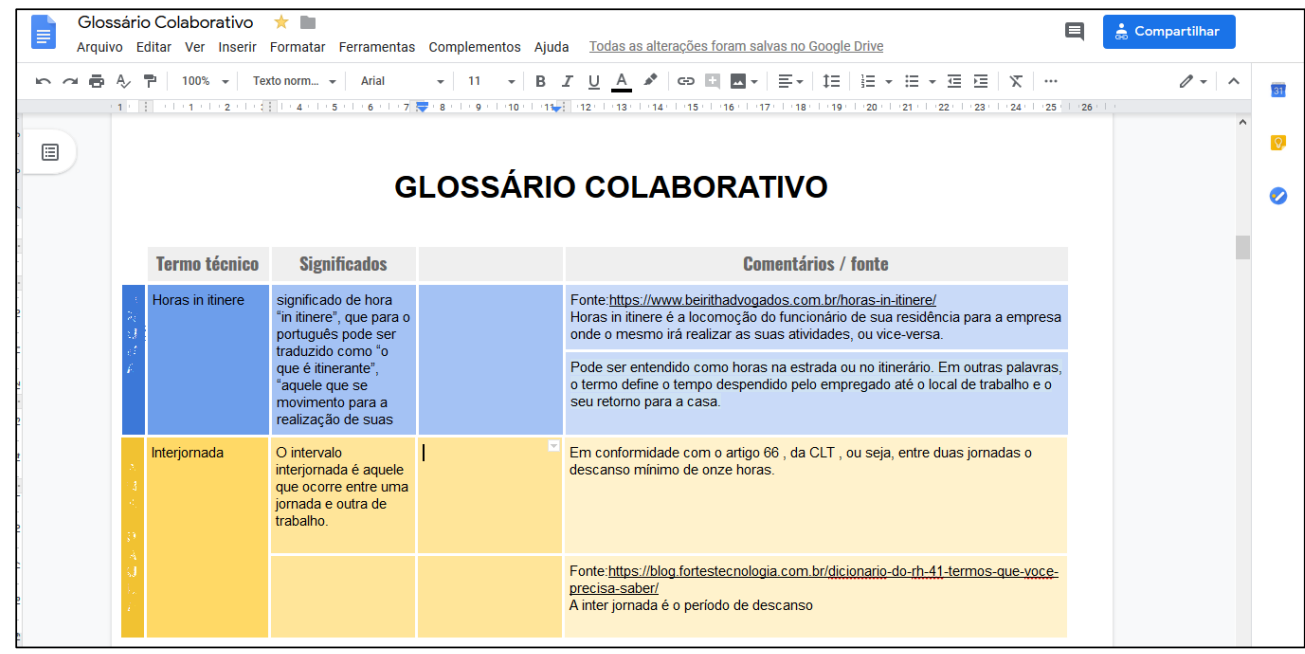

Figura 4 - Glossário Colaborativo - criado no Google classroom pelo Google docs. Fonte: Elaborado pelo autor, com base na pesquisa realizada.

Os resultados evidenciaram a partir da observação da colaboração e utilização do $e$ learning, na última atividade que a aplicação não foi muito positiva pois, os alunos tiveram muitos problemas com formatação do texto, uma vez que o arquivo é totalmente editável e cada aluno desejava fazer sua própria edição.

Outro ponto evidente foi uma baixa parcela de alunos que realizaram atividade a distância, a grande maioria concluiu o trabalho em sala de aula. O maior destaque apontado pelos alunos, foi a colaboração, onde todos conseguiam editar o mesmo documento, ajudavam-se simultaneamente e corrigiam possíveis erros ortográficos e de concordâncias.

Diante de toda perspectiva da sequência didática, é perceptível que o e-learning como ferramenta híbrida é válida, destacando a interação da turma em um contexto geral de todas as atividades.

Outro ponto importante, é a forma que o e-learning foi utilizado, todas as atividades foram inseridas em uma perspectiva pedagógica, com intuito de proporcionar aos estudantes uma realização independente, refletindo positivamente em trabalhos presenciais, caracterizando favoravelmente ao cenário de ensino híbrido, como aponta os autores: 
Tais recursos traz a ludicidade para o campo da aprendizagem, configurando-se como prazeroso para os alunos, através da participação interativa, fazendo a transposição didática entre o conteúdo e as tecnologias. Assim, os jovens aprendem com o que lhes é diretamente ensinado e desenvolvem padrões de participantes nas práticas desenvolvidas em cada comunidade[...]" (LIMA; MOITA, 2011, p. 150).

Dessa forma, a sequencia didática resultou um aspecto positivo e colaborativo entre os alunos, mesmo tendo algumas dificuldades na terceira atividades, apontaram um bom aproveitamento colaborativo.

\section{CONSIDERAÇÕES FINAIS}

A partir da experiência realizada conclui-se que o $e$-learning foi a base para aplicação e execução das atividades realizadas, uma vez que todas as atividades elaboradas utilizaram o ensino com recursos eletrônicos.

Ao decorrer do trabalho aplicado, foi possível notar benefícios ao utilizar o e-learning, várias práticas foram produzidas utilizando esse recurso, demostrando enriquecer e alavancar o processo de ensino-aprendizagem, uma vez que o e-learning foi evidenciado como meio facilitador no processo de construção do conhecimento, proporcionando significativo desempenho, liberdade, autonomia e equidade aos alunos.

Foi evidente que o Google sala de aula possui vários recursos que contribuem para interação da turma, expandindo formas de consolidar conteúdos e atividades, além de poder criar novas formas de ensinar, favorecendo o professor a criar estratégias e metodologias para que esse recurso seja inserido de forma pedagógica.

Outro ponto importante foi o significativo uso da metodologia híbrida como processo de ensino-aprendizagem, os alunos conseguiram ler o conteúdo da disciplina e realizar atividades a distância, envolvendo-se e participando ativamente nas aulas presenciais.

Além disso, o aprendizado colaborativo foi um dos pontos forte, em todas atividades essa metodologia foi utilizada, fazendo que cada estudante expressasse auxilio e apoio em conjunto, visto que, a colaboração é muito bem aceita pela grande maioria dos estudantes. 


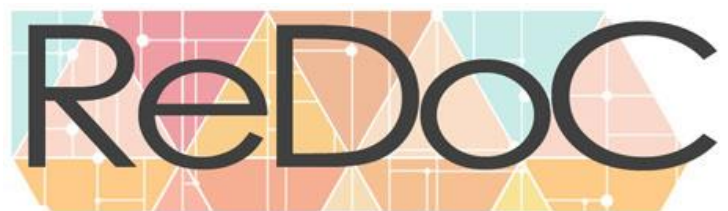

\section{Revista Docência e Cibercultura}

Nesse sentido, compreende-se que o e-learning consegue corroborar e alavancar o processo de ensino e aprendizagem. Todavia, a base está no conjunto de diretrizes dos processos educacionais, compreendendo o papel do professor como mediador da tecnologia/aluno e a efetiva participação do estudante com o ensino híbrido.

Assim, é notório que a utilização do e-learning é uma metodologia que vem sedo praticada por vários docentes, porém, que está mudando vagarosamente a forma tradicional de ensinar, onde não existe uma forma pronta de inserir o recurso na sala de aula, uma vez que, cada turma, cada disciplina e cada professor terá uma necessidade específica sobre a melhor forma de inteira-se com o contexto educacional.

Portanto, a utilização do ensino eletrônico, não caracteriza um total sucesso no ensinoaprendizado do aluno, mas tende a ser uma ferramenta colaborativa a partir de novas estratégias que os professores propõem, destacando sempre que a tecnologia por si só não consegue proporcionar um total ensino para turma, necessitando da mediação do professor, refletindo em novas metodologias com os alunos.

\section{REFERÊNCIAS}

ANDRADE, Maria Margarida. Como Preparar Trabalhos Para Cursos de Pós-graduação: Noções Práticas. 5.ed. São Paulo: Atlas, 2002.

BACICH, Lilian; MORAN, José. Metodologias ativas para uma educação inovadora: uma abordagem teórico-prática. Porto Alegre: Penso Editora, 2018.

BACICH, Lilian; NETO, Adolfo Tanzi; DE MELLO TREVISANI, Fernando. Ensino híbrido: personalização e tecnologia na educação. Porto Alegre: Penso Editora, 2015.

BELLONI, Maria Luiza. O que é mídia-educação. Campinas, São Paulo: Autores Associados, 2001.

BRANSFORD, John. D. et al. How people learn. Washington, DC: National academy press, 2000.

BRASIL. Decreto $n^{\circ} 9.057$ de 25 de maio de 2017. Regulamenta o art. 80 da Lei $n^{\circ} 9.394$, de 20 de dezembro de 1996, que estabelece as diretrizes e bases da educação nacional. Diário Oficial da União, 2017.

Cardoso, Fernando de Carvalho. Gestores de e-learning: saiba planejar, monitorar e implantar o e-learning para treinamento corporativo. São Paulo: Saraiva, 2007. 


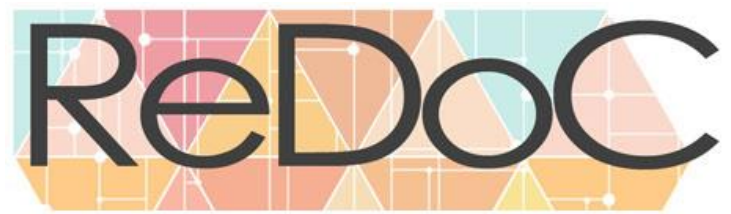

\section{Revista Docência e Cibercultura}

CASTELLS, Manuel. A sociedade em rede. 2.ed. Rio de Janeiro: Paz e Terra, 2009.

CASTRO, Marcelo de. et al. Metodologia colaborativa com suporte da tecnologia: uma aplicação docente. 2018. Dissertação (Dissertação em Tecnologia da Inteligência e Designer Digital) - PUC. São Paulo, p. 16. 2018.

DE ARAÚJO, Denise Lino. O que é (e como faz) sequência didática? Entre palavras, v. 3, n. 1, p. 322-334, 2013.

GIL, Antônio Carlos. Métodos e técnicas de pesquisa social. 6.ed. São Paulo: Atlas, 2008.

Gomes, Maria João. E-Learning: Reflexões em torno do conceito. In P., Dias \& V., Freitas (orgs.), Actas da IV Conferência Internacional de Tecnologias de Informação e Comunicação na Educação - Challenges'05. Braga: Centro de Competência da Universidade do Minho, 229-236, 2005.

LÉVY, Pirre; AUTHIER, Michel. As árvores de conhecimentos. São Paulo: Escuta, 2000.

LIMA, Rosana Passos de Oliveira Lima; MOITA, Maria Gonçalves da Silva Cordeiro Moita. A tecnologia e o ensino de química: jogos digitais como interface metodológica. Campina Grande: EDUEPB, 2011.

LOPES, Maria Cristina et al. O processo histórico da educação a distância e suas implicações: desafios e possibilidades. VII Jornada Do Histedbr, Campo Grande, v. 22, 2007. Disponível em: http://www.histedbr.fe.unicamp.br/acer_histedbr/jornada/jornada7/03trab-gt-gt1.htm. Acesso em: 13 jan. 2020.

MARTINS, José et al. Network Based Model For E-Learning 2.0. Procedia-Social and Behavioral Sciences, v. 47, p. 1242-1248, 2012.

MAYRING, Philipp. Introdução à pesquisa social qualitativa: uma introdução para pensar qualitativamente. 2002.

MOORE, Michel G. et al. Educação a distância: uma visão integrada. São Paulo: Cengage Learning, 2007.

MORAN, José. Educação híbrida: um conceito-chave para a educação, hoje. Ensino híbrido: personalização e tecnologia na educação. Porto Alegre: Penso, p. 27-45, 2015.

MOURA, Adelina. Mobile learning: metodologias, ferramentas e práticas educativas.

Portucalense University, Portugal, dez. 2017. Disponível em: https://www.

researchgate.net/publication/322132657. Acesso em: 20 jan 2020.

PEREIRA, Eva Waisros; MORAES, Raquel de Almeida. História da EaD e os desafios na formação de professores no Brasil. In: SOUZA, A. M. de; FIORENTINI, L. M. R; (Orgs.) et.al. Educação superior a distância - comunidade de trabalho e aprendizagem em rede (CTAR). Brasília: Universidade de Brasília, Faculdade de Educação, 2009. 


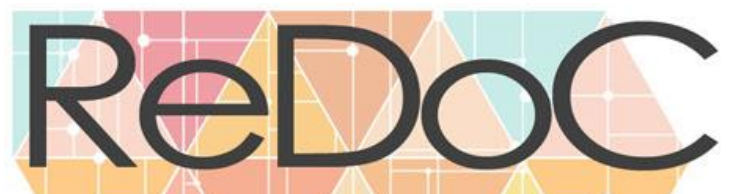

\section{Revista Docência e Cibercultura}

PRENSKY, Marc. Nativos digitais, imigrantes digitais. On the horizon, v. 9, n. 5, p. 1-6, 2001.

ROJO, Roxane. Letramentos digitais: a leitura como réplica ativa. Trabalhos em Linguística Aplicada, v. 46, n. 1, p. 63-78, 2007.

RUHE, Valerie; ZUMBO, Bruno D. Avaliação de educação a distância e e-learning. Porto Alegre: Penso Editora, 2015.

SANGRÀ, Morer Albert et al. Hacia una definición inclusiva del e-learning. BarcelonaUOC: e-Learning Center, 2011.

SCHLOSSER, Lee Ayers; SIMONSON, Michael R. Distance Education: Definitions and Glossary of Terms. IAP, 2009.

SUNAGA, Alexandro; CARVALHO, Camila S. As tecnologias digitais no ensino híbrido. Ensino híbrido: personalização e tecnologia na educação. Porto Alegre: Penso, p.141-154, 2015.

VALENTE, José Armando. O ensino híbrido veio para ficar. Prefácio. In: BACICH, Lilian; NETO, Adolfo Tanzi; DE MELLO TREVISANI, Fernando. Ensino híbrido: personalização e tecnologia na educação. Porto Alegre: Penso, 2015.

WITT, Dan. Accelerate Learning with Google Apps for Education. 2015. Disponível em: https://danwittwcdsbca.wordpress.com/2015/08/16/accelerate-learning-with-google-apps-foreducation/. Acesso em: 10 jan. 2020.

Este é um artigo de acesso aberto distribuído sob os termos da Licença Creative Commons Atribuição Não Comercial-Compartilha Igual (CC BYNC- 4.0), que permite uso, distribuição e reprodução para fins não comerciais, com a citação dos autores e da fonte original e sob a mesma licença. 